\section{Massive haemoptysis complicating prosthetic patch pulmonary embolism after atrial septal defect repair}

\author{
M Haro, J Ruiz, J Ribas, J Maestre, \\ J Pérez-Piteira, J Morera
}

\begin{abstract}
A case is presented of a $\mathbf{4 3}$ year old woman with massive haemotypsis secondary to non-thrombotic pulmonary embolism complicating atrial septal defect repair with a prosthetic patch. Non-thrombotic embolus must be considered in the differential diagnosis of massive haemoptysis.

(Thorax 1995;50:911-912)
\end{abstract}

Keywords: atrial septal defect, non-thrombotic pulmonary embolism.

Thoracic Surgery

Service

J Maestre

Pathology Service J Pérez-Piteira

Germans Trias i Pujol Hospital,

Badalona,

Spain

Reprint requests to: Dr M Haro Estarriol, Sección de Neumología (Planta 2), Hospital General de Albacete, c/Hermanos

Falcó, s/n, 02006 Albacete

Spain

Received 9 June 1994

Returned to authors

29 July 1994

Revised version received

26 August 1994

26 August 1994

Accepted for publica

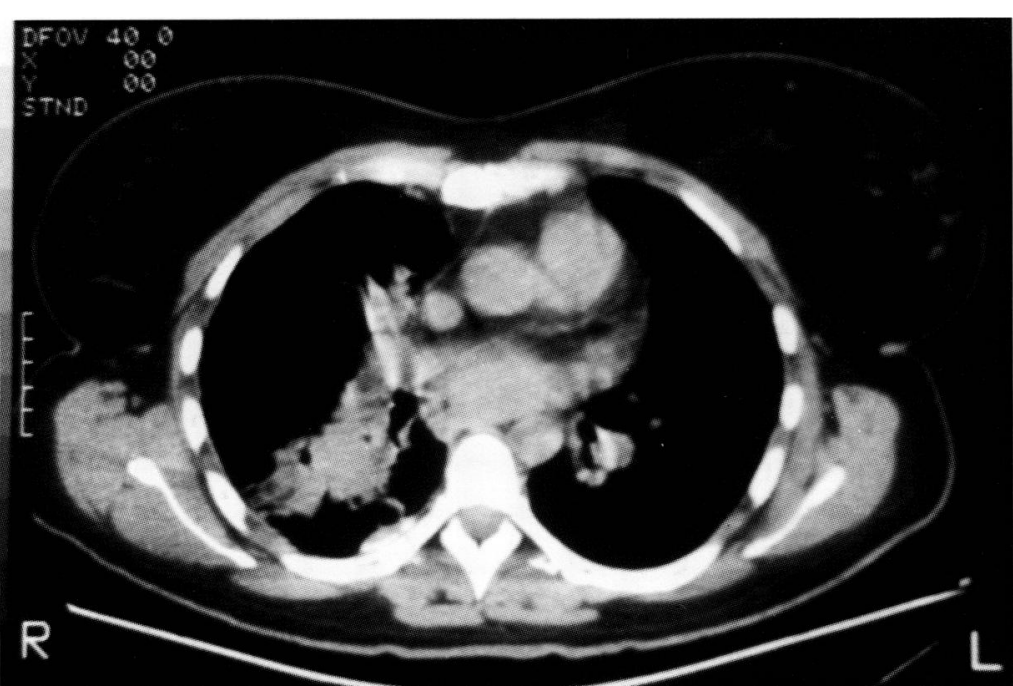

\section{Case report}

A 43 year old non-smoking white woman was admitted with massive haemoptysis. There was

Atrial septal defect is one of the most commonly recognised congenital cardiac anomalies in adults. Uncomplicated atrial septal defect in which there is evidence of significant left-toright shunting may be closed by suture or with a prosthetic patch. ${ }^{1}$ The surgical mortality and morbidity rate is low and results are generally excellent. ${ }^{1}$ We report a case of massive haemoptysis complicating prosthetic patch pulmonary embolism 20 years after repair of the atrial septal defect.

Figure 1 Computed tomographic scan showing apical right lower lobe infiltrate. a history of atrial septal defect, ostium secundum type, that was first noted at the age of 20 years and closed with an interatrial prosthetic patch without surgical complications. She was well until two years before admission when haemoptysis developed. A chest radiograph showed an apical right lower lobe infiltrate; subsequent bronchoscopic examination was normal. A tuberculin skin test was negative and sputum study disclosed no acid fast bacilli. She remained asymptomatic until admission when she presented with a two day history of cough with blood-tinged sputum, followed by considerable haemoptysis (approximately $500 \mathrm{ml}$ in 24 hours). Physical examination was normal; in particular, cardiac auscultation revealed normal heart sounds. Laboratory tests were normal, as were the electrocardiogram, pulmonary function tests, and arterial blood gas analysis (breathing room air). A computed tomographic (CT) scan of the thorax confirmed the infiltrate to be in the apical segment of the right lower lobe (fig 1). When intravenous contrast medium was administered she experienced a hypersensitivity skin reaction and it was stopped. An initial bronchoscopic examination showed active bleeding from the right lower lobe. On the seventh hospital day a second bronchoscopic examination showed inflamed bronchial mucosa in the apical segment of the right lower lobe but no endobronchial lesion could be seen. Microbiological and cytological examination of bronchoalveolar lavage fluid, bronchial washings, and biopsy specimens revealed no fungi, acid fast bacilli, or atypical cells. Pulmonary angiography was not performed because of the hypersensitivity reaction to contrast material during CT scanning. Thoracotomy was performed because of repeated haemoptysis. After resection of the right lower lobe dissection of the lobar pulmonary artery demonstrated the interatrial prosthetic patch within one of its segmental branches (fig 2). Microscopically it was surrounded by inflammatory fibrous tissue similar to a foreign body giant cell reaction. Three days after surgery a colour echocardiogram confirmed the permeability of the atrial septal defect.

\section{Discussion}

Life threatening haemoptysis is rare, occurring in less than $5 \%$ of all patients who present with haemoptysis. The mortality with conservative treatment is as high as $75 \% .^{23}$ The incidence of a cardiovascular cause of haemoptysis has varied from 1.4 to $7 \% .^{1-3}$ Well recognised cardiovascular causes of massive haemoptysis include mitral stenosis and congenital heart disease. Other causes are septic pulmonary emboli complicating bacterial endocarditis, mycotic aneurysms of the pulmonary artery, dissection of the aorta, and bronchovascular fistulae. ${ }^{4-6}$ Cases of massive haemoptysis have been reported with prosthetic mitral valve obstruction and with automatic implantable cardioverter defibrillator placement. ${ }^{78}$ Haemoptysis complicating congenital heart disease has been most frequently described in pulmonary 


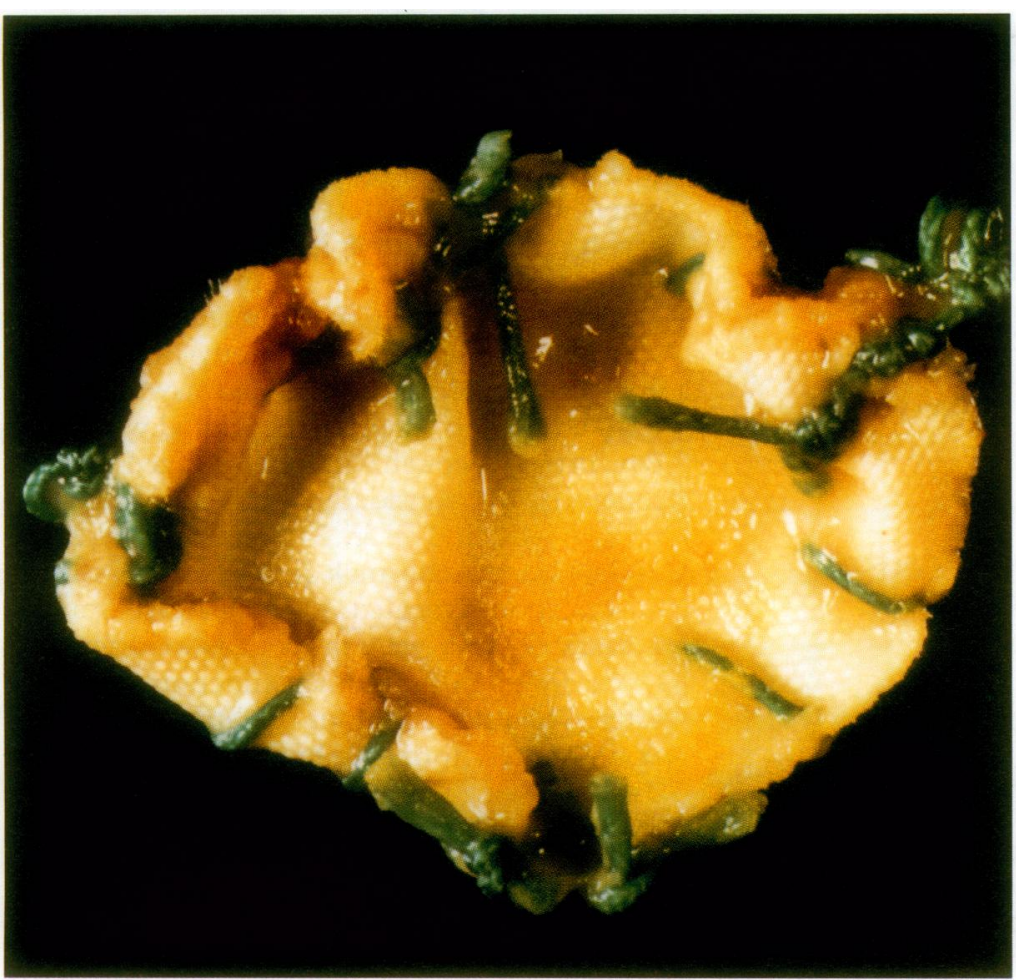

Figure 2 Interatrial prosthetic patch after surgical resection of the right lower lobe.

vascular disease, usually with pulmonary arterial stenosis and Eisenmenger's complex, but it also occurs in patients with pulmonary venous congestion, as in atrial septal defect with significant left-to-right shunting. ${ }^{23}$ Early surgical repair is definitive and results are generally excellent without significant complications. ${ }^{1}$ To our knowledge this is the first reported case of massive haemoptysis complicating prosthetic patch pulmonary embolism after atrial septal defect repair. We believe that the patch had detached shortly after surgery and lodged in a segmental pulmonary artery, and bled as a result of a local vigorous inflammatory response and foreign body reaction with repeated infections. New vessel formation and extensive remodelling with hypertrophy of the bronchial artery was present, as would occur with an aspergilloma. ${ }^{23}$ This possibility is supported by the bronchoscopic, radiographic, and microscopic findings.

Foreign particle embolism can be derived from almost any material introduced into the body. Usually it embolises to the lungs and may cause little damage, but occasionally it may result in interstitial fibrosis and/or pulmonary hypertension. In our case the dislodgement of the prosthetic patch was complicated by an increased inflammatory response and bleeding. Cases have been reported of systemic embolisation of a prosthetic mitral valve and tricuspid valve fragments to the lungs, but have not presented as massive haemoptysis or related to atrial septal defect prosthetic patch. ${ }^{9}$

1 Alpert JS, Rippe JM. Congenital heart disease. In: Manual of cardiovascular diagnosis and therapy. Boston: Little Brown, 1988:235-54.

2 Israel RH, Poe RH. Haemoptysis. Clin Chest Med 1987;2: 197-205.

3 Thompson AB, Teschler H, Rennard SI. Pathogenesis, evaluation and therapy for massive haemoptysis. Clin Chest Med 1992;1:69-82.

4 Cosmo LY, Risi G, Nelson S, Subramanian P, Martin D, Haponik E. Fatal haemoptysis in acute bacterial endocariditis. Am Rev Respir Dis 1988;137:1223-6.

5 Morgan JM, Morgan AD, Addis B, Bradley GW, Spiro SG. Fatal haemorrhage from mycotic aneurysms of the pulmonary artery. Thorax 1986;41:70-1.

6 Scarlat A, Bodner G, Liron M. Massive haemoptysis as the presenting symptom in mitral stenosis. Thorax 1986;41: presenting.

7 Kao N, Messersmith RN, Klich J. Haemoptysis complicating AICD patch placement controlled by temporary selective bronchial balloon occlusion. Chest 1991;99:1301-3.

8 Michielon G, Mullany CJ, Viggiano RW, Mark Brutinel W. Massive pulmonary haemorrhage complicating mitral prosthetic valve obstruction. Chest 1993;103:1903-5.

9 Adler DS. Nonthrombotic pulmonary embolism. In Goldhaber SZ, ed. Pulmonary embolism and deep venou thrombosis. Philadelphia: WB Saunders, 1985:209-41. 